\title{
Yetişkin hastalarda Schatzki halkası: 3. basamak merkezi deneyimi
}

\author{
Schatzki ring in adult patients: Experience of tertiary stage center
}

Mustafa KAPLAN, Volkan GÖKBULUT, Orhan COŞKUN, Adem AKSOY, Erkin ÖZTAŞ, Ertuğrul KAYAÇETIN

Türkiye Yüksek Ihtisas Eğitim ve Araş̧trma Hastanesi, Gastroenteroloji Kliniği, Ankara

\begin{abstract}
Giriş ve Amaç: Shatzki halkası özofagus alt kısmında lümeni halka veya yüzük şeklinde daraltan yapılardır. Bu çalışmada Shatzki halkasının endoskopik bulgular ve diğer hastalıklar ile ilişkisini araștırmayı amaçladık. Gereç ve Yöntem: Bu çalışma Ocak 2014-Aralık 2015 tarihleri arasında endoskopi yapılan hastaların kayıtları incelenerek retrospektif olarak yapılmıştır. Toplamda 5.000 endoskopi kaydı incelenmiş ve Shatzki halkası tespit edilen 104 hasta çalışmaya dahil edilmiştir. Bulgular: Araştırma popülasyonu 46 kadın $(\% 44,2)$ ve 58 erkek $(\% 55,8)$ erkek hasta olmak üzere 104 kişiden oluştu. Hastaların ortalama yaşı $60,8 \pm 14,1$ yıldı. Hastaların en sık başvuru endikasyonları disfaji $(\% 26)$, dispepsi $(\% 38,5)$ ve karın ağrısı $(\% 28,8)$ idi. Endoskopi bulguları incelendiğinde hastalarn \%53,8'inde reflü özofajit, \%50'sinde hiatal herni tespit edildi. Özofageal divertikül \%4,8, başka web $\% 1$, özofageal ülser \%5.7, özofageal polip \%0,9, özofagus varisleri \%1,9, özofagus motilite bozuklukluğu (hipertrofik alt özofagus sfinkteri) \%1,9 ve Barrett özofagus \%3,8 hastada tespit edildi. Hastalarn \%58'inde Helicobacter pylori, \%19'unda demir eksikliği anemisi ve \%5,7'sinde vitamin B12 eksikliği saptandı. Sonuç: Shatzki halkası aralıklı disfajinin önemli sebeplerinden biri olup reflü özofajit, hiatal herni ve demir eksikliği anemisi ile birliktelik göstermektedir.
\end{abstract}

Anahtar kelimeler: Özofageal web, reflü özofajit, hiatal herni, demir eksikliği anemisi, disfaji

\section{GİRISS}

Özofagus halkaları özofagus alt kısmında lümeni halka şeklinde daraltan yapilardır (1). Kas veya mukoza tabakasından kaynaklanabilirler. Daha nadir görülen müsküler halka konjenitaldir ve mukozal halkalara göre daha nadir görülür. Mukozal halkalar ise daha sık görülen ve özofagogastrik bileşkenin hemen üzerinde görülen mukozal oluşumlardır. Schatzki halkası (SH) ise en sık görülen özofagus halkasıdır. Hastalar çoğunlukla asemptomatik olmasına rağmen, erişkinlerde katılara karşı olan epizodik disfaji ve gıda sıkışmasının en sık sebeplerinden biri olarak kabul edilmektedir. Tanı baryumlu grafi veya üst endoskopi ile konulur (2). SH değişik nedenlerle yapilan üst gastrointestinal endoskopilerin \%4-15'inde tespit edilmiştir (3). SH'nın etiyolojisi ve patogenezi tam olarak bilinmemekle beraber gastroözofageal reflü hastalığına (GERH) bağlı kronik hasar, Barrett özofagus, konjenital sebepler, eozinofilik özofajit gibi hastalıklar suçlanmaktadır (4-7). Ancak ülkemizde SH ile yapılmış herhangi bir çalışma bulunmamaktadır. Biz bu çalışmada 3. basamak bir merkez-
Background and aim: The Schatzki ring is a ring-shaped luminal constriction in the lower part of the esophagus. In this study, we aimed to investigate the relationship of the Schatzki ring with endoscopic findings and other diseases. Material and Methods: This study was retrospectively conducted by examining the records of patients who underwent endoscopy between January 2014 and December 2015. A total of 5.000 endoscopic recordings were examined, and 104 patients with Schatzki ring were included in the study. Results: The study population consisted of 104 patients, 46 (44.2\%) female and $58(55.8 \%)$ male. The mean patient age was $60.8 \pm 14.1$ years. The most frequent admission indications were dysphagia (26\%), dyspepsia (38.5\%), and abdominal pain (28.8\%). When endoscopic findings were examined, $53.8 \%$ of patients had reflux esophagitis and $50 \%$ had hiatal hernia. Esophageal diverticulum was present in $4.8 \%$; other esophageal web, in $1 \%$; esophageal ulcer, in 5.7\%; esophageal polyp, in 0.9\%; esophageal varices, in 1.9\%; esophagus motility disorder (hypertrophic lower esophageal sphincter), in 1.9\%; and Barret's esophagus, in 3.8\%. Helicobacter pylori was diagnosed in 58\% of patients; iron deficiency anemia, in 19\%; and B12 deficiency, in 5.7\%. Conclusion: The Schatzki ring is one of the important causes of intermittent dysphagia and is associated with reflux esophagitis, hiatal hernia, and iron deficiency anemia.

Key words: Esophageal web, reflux esophagitis, hiatal hernia, iron deficiency anemia, dysphagia

de üst gastrointestinal endoskopide SH tespit edilen hastalarda SH ile endoskopik bulgular ve diğer hastalıkların ilişkisini araştırmayı amaçladık.

\section{GEREC ve YÖNTEM}

Bu çalışma Ocak 2014-Aralık 2015 tarihleri arasında Türkiye Yüksek Ihtisas Hastanesi Gastroenteroloji Kliniği’nde çeşitli sebeplerle endoskopi yapılan hastaların hasta kayıtları incelenerek retrospektif olarak yapılmıştır. Endoskopik inceleme sonucunda SH tespit edilen hastalar çalışmaya dahil edilmiştir. Toplamda 5.000 endoskopi kaydı incelenmiş, SH tespit edilen 110 hasta bulunmuş, veri eksikliği olan 6 hasta çalışmadan çıkarıldıktan sonra 104 hasta çalışmaya dahil edilmiştir.

Hastaların başvuru şikayetleri ve demografik özellikleri dosyalarından kaydedilmiştir. Hastaların endoskopi bulguları incelenmiş ve özofageal ve gastrik bulgular not edilmiştir. 
Tablo 1. Schatzki halkası görülen hastaların demografik ve klinik özellikleri

\begin{tabular}{|c|c|}
\hline Değişkenler & $\mathbf{N}(\%)$ \\
\hline Yaş & $60,8 \pm 14,1$ \\
\hline \multicolumn{2}{|l|}{ Cinsiyet } \\
\hline Kadın & $46(44,2)$ \\
\hline Erkek & $58(55,8)$ \\
\hline \multicolumn{2}{|l|}{ Endikasyon } \\
\hline Disfaji & $27(26)$ \\
\hline Dispepsi & $42(38,5)$ \\
\hline Karın ağrısı & $30(28,8)$ \\
\hline Diğer (kanama-bulantı/kusma) & $5(4,8)$ \\
\hline Reflü özofajit (Los Angeles sınıflaması) & $56(53,8)$ \\
\hline A & $34(32)$ \\
\hline $\mathrm{B}$ & $17(16)$ \\
\hline C & $4(3.8)$ \\
\hline $\mathrm{D}$ & $1(0,9)$ \\
\hline Hiatal herni & $52(50)$ \\
\hline Özofageal divertikül & $5(4,8)$ \\
\hline Başka web & $1(0,9)$ \\
\hline Özofageal ülser & $6(5,7)$ \\
\hline Özofageal polip & $1(0,9)$ \\
\hline Özofagus varisi & $2(1,9)$ \\
\hline Motilite bozukluğu (HAÖS) & $2(1,9)$ \\
\hline Barrett özofagus & $4(3,8)$ \\
\hline \multicolumn{2}{|l|}{ Gastrik bulgular } \\
\hline Pangastrit & $56(53)$ \\
\hline Antral gastrit & $34(32)$ \\
\hline Bulbit & $15(14)$ \\
\hline Gastrik/bulber ülser & $6(5,7)$ \\
\hline Gastrik polip & $2(1,8)$ \\
\hline Opere mide & $3(2,8)$ \\
\hline Helicobacter pylori & $58(55)$ \\
\hline
\end{tabular}

HAÖS: Hipertrofik alt özofagus sfinkteri

Tablo 2. Schatzki halkası ile diğer hastalıkların ilișkisi

$\begin{array}{ll}\text { Değişkenler } & \text { N (\%) } \\ \text { Demir eksikliği anemisi } & 20(19) \\ \text { B12 eksikliği } & 6(5,7) \\ \text { Hipotiroidi } & 2(1,9) \\ \text { Hipertiroidi } & 0 \\ \text { Otoimmün hastalıklar } & 1(0,9)\end{array}$

Özofagogastrik bileşkedeki ince simetrik mukozal yapılar SH olarak kabul edilmiştir (1). Gastrik mukozanın diafragmın $1.5 \mathrm{~cm}$ yukarısına uzanması hiatal herni olarak kabul edilmiştir (8). Reflü özofajit sınıflaması için Los Angeles sınıflaması kullanılmıştır (9). Helicobacter pylori (H. pylori) pozitifliği için üç testen herhangi birinde (patoloji, üre nefes testi veya dışkı) H. pylori pozitif çıkması esas alınmışıı. Hikayesinde veya tanı anında demir eksikliği anemisi, B12 eksikliği, hipotiroidi, hipertroidi veya otoimmün hastalığı olanlar kaydedilmiştir. Istatistiksel değerlendirme Statistical Package for Social Sciences (SPSS) for Windows 20 (IBM SPSS Inc., Chicago, IL) programı kullanılarak yapılmıştır. Verilerin normal dağılımı Kolmogorov-Smirnov testi ile değerlendirilmiștir. Sayısal değişkenlerden normal dağllım sergileyenler ortalama standart sapma olarak, normal dağılım sergilemeyenler ortanca (min-max) olarak gösterilmiştir. Kategorik değişkenler sayı ve yüzde olarak belirtilmiştir.

\section{BULGULAR}

Araştırma popülasyonu 46 kadın $(\% 44,2)$ ve 58 erkek $(\% 55,8)$ erkek hasta olmak üzere 104 kişiden oluştu. Hastaların ortalama yaşı $60,8 \pm 14,1$ yıldı. Çalışmamızda SH oranı $\% 2$ bulunmuştur. Hastaların en sık başvuru endikasyonları disfaji (\%26), dispepsi $(\% 38,5)$, karın ağrısı $(\% 28,8)$ ve bulantı, kusma ve kanama gibi diğer endikasyonlardı $(\% 4,8)$. Endoskopi bulguları incelendiğinde hastaların \%53,8'inde reflü özofajit tespit edildi. Los Angeles siniflamasina göre bu hastaların \%32'sinde grade A, \%16'sinda grade B, \%3,8'inde grade $\mathrm{C}$ ve $\% 0,9$ 'unda grade $\mathrm{D}$ reflü özofajit mevcuttu. Hastaların yarısında hiatal herni mevcuttu. Özofageal divertikül oranı $\% 4,8$, özofageal ülser oranı $\% 5,7$, özofageal polip oranı $\% 0,9$, özofagus varisleri oranı \%1,9, özofagus motilite bozuklukluğu (hipertrofik alt özofagus sfinkteri) oranı \%1,9, Barrett özofagus oranı \%3,8 idi. Bir hastada $(\% 0,9)$ özofagus proksimalinde demir eksikliğine bağlı diğer bir web izlendi. Hastaların diğer endoskopik bulguları incelendiğinde \%53 hastada pangastrit, \%32 hastada antral gastrit, \%14 hastada bulbit, \%5,7 hastada gastrik veya bulber ülser, \%1,8 hastada gastrik polip ve $\% 2,8$ hastada opere mide izlendi. Hastaların \%58'inde H. pylori (+) saptandı. Schatzki halkası görülen hastaların demografik ve klinik özellikleri Tablo l'de özetlenmiştir.

SH tespit edilen hastaların laboratuvar ve klinik bulguları incelendiğinde hastaların \%19'unda demir eksikliği anemisi, \%5,7'sinde B12 eksikliği, \%1,9'unda hipotiroidi ve $\% 0,9$ 'unda otoimmün hepatit olduğu tespit edildi. Schatzki halkası ile diğer hastalıkların ilişkisi Tablo 2'de özetlenmiştir.

\section{TARTISQMA}

Bu çalışmada 5.000 endoskopi kaydı incelenmiş ve \%2 hastada SH tespit edilmiştir. SH'nin reflü özofajit, hiatal herni 
ve demir eksikliği anemisi ile sık birliktelik gösterdiği bulunmuştur. Bu çalışma ülkemizde SH ile ilgili yapılmış ilk çalışmadır.

Çalışmamızda SH oranı \%2 olarak bulunmuştur. Daha önce Towbin ve ark. çocuk hastalarda yaptığı çalışmada ise oran $\% 0.2$ olarak bildirilmiştir (10). Bu çalışmanın çocuk hastalarla yapılması nedeniyle reflü özofajit gibi önemli bir etiyolojik faktörün çocuklarda daha az sıklıkla görülmesinin bu farklılığa sebep olabileceğini düşünüyoruz. Ayrıca daha önce yapilmış çalışmalarda endoskopide SH tespit oranının \%415 arasında değişebildiği belirtilmektedir (3). Bizim çalışmamizda ise 5.000 endoskopi kaydının incelenmesi sonucunda böyle bir orana ulaştığımız için bu oranın daha kullanılabilir olduğunu düşünüyoruz.

Çalışmamızda SH tespit edilen hastaların ortalama yaşı 60 olarak bulunmuştur. Daha önce yapılan bir çalışmada ise ortalama yaş 57 olarak bulunmuştur (5). Bu sonuçlara göre SH'nin yaşlı hastalarda daha sık rastlanılan bir bulgu olduğunu söyleyebiliriz. Çalışmamızda hastaların en sık başvuru semptomları karın ağrısı, dispepsi ve disfajidir. Literatür taramamızda SH olan hastaların daha çok asemptomatik olduğu, semptomatik olanların ise katı gıda disfajisi ile hastaneye başvurduğu belirtilmektedir (2). Çalışmamızdaki hastaların yaklaşık üçte birinde disfaji şikayetinin olması nedeniyle SH'nin disfaji etiyolojisinde önemli bir yeri olduğunu düşünüyoruz.

Daha önce yapılan bir çalışmada hiatal herni oranı \%97 bulunurken reflü özofajit oranı \%28 bulunuştur (5). Bizim çalışmamızda ise hastalarımızın \%56'sında reflü özofajit ve yarısında ise hiatal herni tespit edilmiştir. Bu da hastalığın etiyolojisinde bu iki durumun yol açtığı kronik mukozal hasarın önemli bir rolü olduğunu düşündürmektedir. Levin ve ark. yaptığı çalışmada GERH olanların \%22'sinde SH tespit edilmesi de bu kuvvetli ilisskiyi desteklemektedir (11). Ayrıca daha önce yapılan çalışmalarda reflünün hastaların nerdeyse üçte ikisinde görüldügü, reflüye bağlı inflamasyon teorisinin SH oluşumu için en muhtemel etiyolojik faktör olduğu ve anti-reflü tedavisinin de SH tedavisinde kullanılabileceği belirtilmiştir (12-14).

\section{KAYNAKLAR}

1. Schatzki R.The lower esophageal ring. Long term follow-up of symptomatic and asymptomatic rings. Am J Roentgenol Radium Ther Nucl Med 1963;90:805-10.

2. Akın M. Schatzki's ring (Lower esophageal mucosal ring). Turkiye Klinikleri J Gen Surg-Special Topics 2012;5:116-20.

3. Mitre MC, Katzka DA, Brensinger CM, et al. Schatzki ring and Barrett's esophagus: do they occur together? Dig Dis Sci 2004;49:770-3.

4. Chen YM, Gelfand DW, Ott DJ, Munitz HA. Natural progression of the lower esophageal mucosal ring. Gastrointest Radiol 1987;12:93-8.
Çalışmamızda Barrett özofagus oranı \%3,8 olarak bulunmuştur. Mitre ve ark. yaptığı çalışmada ise oran \%0,73 olarak bulunmuştur (3). Bu iki bulgu SH ile Barrett özofagusun ilişkili olmadığını desteklemektedir. Daha önce yapılan çalışmalarda ve bizim çalışmamızda da özofageal divertikül ve motilite bozukluğu oranının \%2-4 civarında olması bu iki durumun SH ile ilişkisinin zayıf olduğunu göstermektedir.

Çalışmamızda H. pylori oranı genel popülasyondan daha düşük saptanmıştır. Ülkemize H. pylori prevalansı \%82 iken (15) bizim çalışmamızda \%58 bulunmuştur. Bunun sebebi ise çalışmaya alınma anında bazı hastaların proton pompa inhibitörü kullanması nedeniyle yanlış negatif sonuçların çıkması olabilir. Diğer bir sebebinin ise H. pylori'nin SH ile olan zayıf ilişskisi olabileceğini düşünüyoruz.

Çalışmamızda \%19 hastada demir eksikliği anemisi görülmüştür. SH tespit edilen hastalarda yüksek oranda görülen reflü özofajit ve buna bağlı özofagus kaynaklı erozyonlar ve kanama olması nedeniyle böyle bir sonuç çıktığını düşünüyoruz. Bilindiği gibi demir eksikliği anemisi üst özofagus webleri ile yakından ilişkilidir ve disfajinin de eşlik ettiği bu durum Plummer-Winson sendromu olarak adlandırılmaktadır. Bizim sonuçlarımız göz önüne alındığında SH'nin de benzer şekilde demir eksikliği anemisi ile ilişkili bir web olabileceği akla gelmektedir. Bu hipotezimizi destekler nitelikte yapılan bir vaka çalışmasında SH ve Plummer-Winson sendromunun beraber görülebileceği belirtilmektedir (16). Bizim çalışmamızda da bu vakaya benzer şekilde bir hastada üst özofagus web ve eşlik eden demir eksikliği anemisi tespit edilmiştir. Daha önce yapılan bir çalışmada ise bizim çalışmamızdan farklı olarak özofagusta başka web oranı \%15,6 olarak bulunmuştur (5).

Çalışmamızın en önemli kısıtlılığı retrospektif yapılmasıdır. Diğer bir önemli kısıtllık ise hastalardan özofageal patoloji alınmaması nedeniyle literatürde SH ile ilişkisinden sıklıkla bahsedilen eozinofilik özofajit ile ilişkisini değerlendirme imkanımızın olmaması idi.

Sonuç olarak SH aralıklı disfajinin önemli sebeplerinden biri olup reflü özofajit, hiatal herni ve demir eksikliği anemisi ile birliktelik göstermektedir.
5. Müller M, Gockel I, Hedwig P, et al. Is the Schatzki ring a unique esophageal entity? World J Gastroenterol 2011;17:2838-43.

6. Nurko S, Teitelbaum JE, Husain K, et al. Association of Schatzki ring with eosinophilic esophagitis in children. J Pediatr Gastroenterol Nutr 2004;38:436-41

7. Müller M, Eckardt AJ, Fisseler-Eckhoff A, et al. Endoscopic findings in patients with Schatzki rings: evidence for an association with eosinophilic esophagitis. World J Gastroenterol 2012;18:6960-6. 
8. Wright RA, Hurwitz AL. Relationship of hiatal hernia to endoscopically proved reflux esophagitis. Dig Dis Sci 1979;24:311-3.

9. Armstrong D, Bennett JR, Blum AL, et al. The endoscopic assessment of esophagits: a progress report on observer agreement. Gastroenterology 1996;111:85-92.

10. Towbin AJ, Diniz LO. Schatzki ring in pediatric and young adult patients. Pediatr Radiol 2012;42:1437-40.

11. Schatzki ring as a symptom of gastroesophageal reflux disease. Levin MD, Mendel'son G. Vestn Rentgenol Radiol 2015;1:5-15.

12. Ott DJ, Ledbetter MS, Chen MY, et al. Correlation of lower esophageal mucosal ring and 24-h pH monitoring of the esophagus. Am J Gastroenterol 1996;91:61-4.

13. Wills JC, Hilden K, Disario JA, Fang JC. A randomized, prospective trial of electrosurgical incision followed by rabeprazole versus bougie dilation followed by rabeprazole of symptomatic esophageal (Schatzki's) rings. Gastrointest Endosc 2008;67:808-13.
14. Sgouros SN, Vlachogiannakos J, Karamanolis G, et al. Long-term acid suppressive therapy may prevent the relapse of lower esophageal (Schatzki's) rings: a prospective, randomized, placebo-controlled study. Am J Gastroenterol 2005;100:1929-34.

15. Ozaydin N, Turkyilmaz SA, Cali S. Prevalence and risk factors of Helicobacter pylori in Turkey: a nationally-representative, cross-sectional, screening with the 13C-Urea breath test. BMC Public Health 2013;13:1215

16. Güngör G, Odabaş Y, Dabak R, et al. Schatzki halkası ile birlikte olan Plummer-Vinson sendromu: Bir olgu sunumu. Akademik Gastroenteroloji Dergisi 2008;7:56-8. 